Dedicated to
dental nursing

Rebecca Smith-Wightman dreamt of working with animals only to discover that those of the human variety were her true calling! Kate Maynard spoke to the award-winning dental nurse.

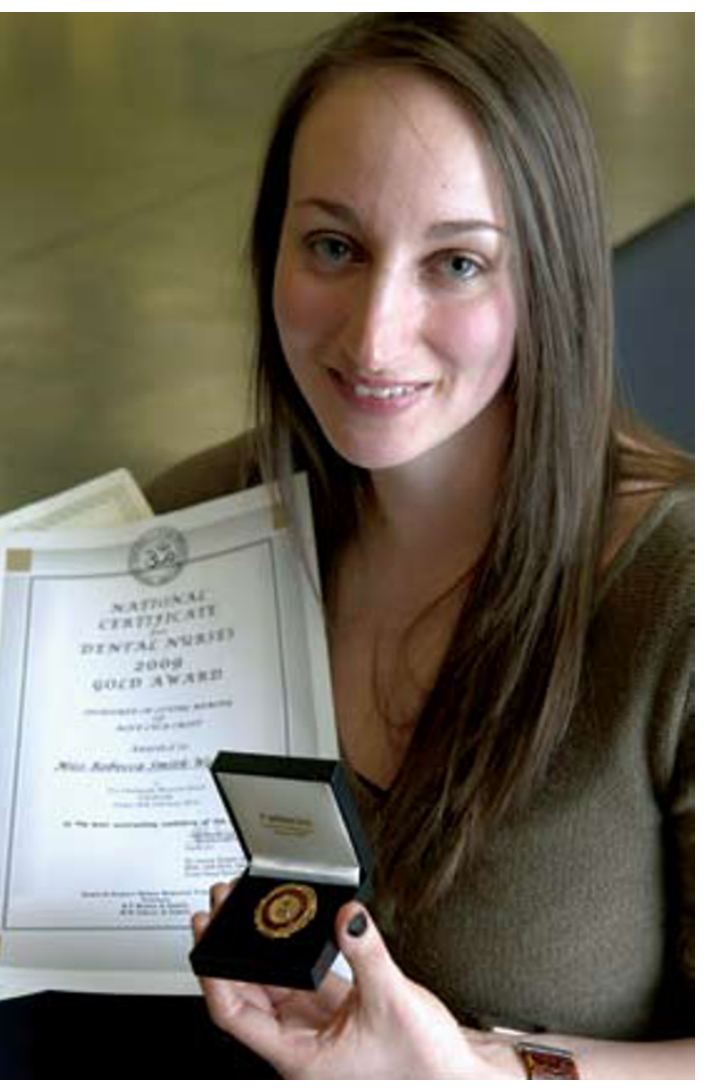

The award

'Winning the NEBDN Gold Award was a big surprise but it was lovely to be recognised for all my hard work, says Rebecca Smith-

Wightman, dental nurse at Mount Wise Dental Practice in Plymouth.

Rebecca received the award at the presentation ceremony for students receiving their National Certificate in Dental Nursing from the National Examining Board for Dental Nurses (NEBDN). She was selected as the most outstanding student out of 3,020 candidates. The board praised Rebecca for being 'knowledgeable, committed and dedicated to dental nursing and the dental profession and willing to share her knowledge and experience with colleagues'.
'I had no idea I was going to receive the award on the night,' says Rebecca. 'It was great that my family and friends could be there to see it.' Rebecca also received a cheque for $£ 200$, a commemorative gold badge and certificate, and The Peninsula Achievement Award (sponsored by Peninsula Dental School) for her commitment to learning and gaining a Distinction in her National Examination.

\section{Animal instinct}

Rebecca's career could have turned out quite differently if she had followed her original ambition:

'After leaving school with eight GCSEs, I wanted to become a veterinary nurse and trained to be one for three years, completing my NVQ Animal Care,' explains Rebecca. But when her friend Claire moved into dentistry as a dental nurse, Rebecca followed suit.

Claire recommended Rebecca when a trainee dental nurse position became available, and that's when Rebecca decided to swap animals for people.

On her first day as a trainee dental nurse, alongside being shown the ropes and introduced to health and safety procedures, Rebecca was able to watch a few hours of dental surgery taking place.

'It was really interesting and I was immediately attracted to being a dental nurse, says Rebecca. 'So many different people came through the door of the practice and so many different situations arose in those few hours. I was intrigued.'

\section{Mount Wise}

Rebecca is one of nine dental professionals working at Mount Wise Dental Practice in Devonport, a district of Plymouth. The team, led by principals Malcolm Prideaux and Bridget Ashton and managed by Marie Cassidy, care for around 2,500 NHS patients from the local community and a number of private patients.
Rebecca worked full time at Mount Wise while studying for her dental nursing qualification, completing her exams in May 2009. Luckily her colleagues were really supportive and gave her revision time. 'They would help me revise and set me spotter tests and other revision tools. I wanted to give my best and so I hit the books and worked as hard as I could.' Rebecca and some of the other dental nurse students held study groups which Rebecca says was 'great, as I was able to bounce ideas off my fellow students.' She found learning about the nervous system particularly difficult to revise but 'kept at it and it soon sank in'.

\section{Team spirit}

Professor Richard Stephenson, Dean of the Faculty of Health and Pro Vice-Chancellor at the University of Plymouth, commented that Rebecca's achievement was 'tremendous and a reward for all of the hard work, commitment and team spirit she demonstrated' while on the course.

Team spirit seems to be in abundance at Mount Wise, who gained Investors in People accreditation in 2003 and BDA Good Practice in 2006 .

'We are a close team who regularly have meetings,' says Rebecca. Practice manager Marie organises CPD activities but staff members also take responsibility for their own additional CPD hours. The team also enjoy a staff barbecue every summer.

Like other dental nurses at the practice, Rebecca would like to go on to gain her Oral Health Education qualification. Indeed, she says that the career possibilities were one of the things that attracted her to dental nursing in the first place.

'I would like to go further in my career and achieve as much as I can,' says Rebecca. 'I enjoy working with the public and with my colleagues. Every day is different and brings something new. There is always something to keep me on my toes.'

\section{Hard work}

When asked what she would say to other young people considering a career as a dental nurse, Rebecca recommends that they should try and get some work experience in a dental practice to make sure that they like it. 'It is a lot of hard work, admits Rebecca. 'But it's very rewarding.'

Rebecca is putting the $£ 200$ that she won with the Gold Award towards her hen weekend and the next challenge on her agenda is planning her wedding in September 2010. We're sure that she will cope with flying colours! 